Check for updates

Cite this: RSC Adv., 2017, 7, 37185

Received 22nd May 2017

Accepted 5th July 2017

DOI: 10.1039/c7ra05732f

rsc.li/rsc-advances

\title{
Graphitic carbon nitride nanosheets obtained by liquid stripping as efficient photocatalysts under visible light
}

\author{
Chengkong Fan, ${ }^{a}$ Jilin Miao, ${ }^{\mathrm{b}}$ Guangqing $\mathrm{Xu}$, (D) *ac Jiaqin Liu, ${ }^{\mathrm{bc}}$ Jun Lv ${ }^{\mathrm{ac}}$ \\ and Yucheng Wu iD *abc
}

\begin{abstract}
Herein, well-scattered $\mathrm{g}-\mathrm{C}_{3} \mathrm{~N}_{4}$ nanosheets were obtained using a liquid stripping method in an ammonia solution at various temperatures. The phase structures, morphologies, and elemental compositions were characterized by X-ray diffraction, transmission electron microscopy, X-ray photoelectron spectroscopy, Raman spectra, and Fourier transform infrared spectroscopy. The nanosheets with sizes of several hundred nanometers can be obtained via liquid stripping. The photocatalytic performance of the g- $\mathrm{C}_{3} \mathrm{~N}_{4}$ nanosheets was measured by degrading $\mathrm{RhB}$ under visible-light illumination. The $\mathrm{g}-\mathrm{C}_{3} \mathrm{~N}_{4}$ (30) nanosheets can achieve the highest degradation rate of $88 \%$ in $60 \mathrm{~min}$, which is 5 times that of bulk g$\mathrm{C}_{3} \mathrm{~N}_{4}$. The mechanisms of the enhancement were studied by discussing the whole photocatalytic process. It has been observed that high specific surface area plays a key role in enhancing the photocatalytic performance.
\end{abstract}

\section{Introduction}

Recently, the increasing global crisis of environmental issues has become a serious threat to the long-term development of human society. The application of $\mathrm{TiO}_{2}$ as a classic semiconductor photocatalyst has been studied for a long time. ${ }^{1}$ Recently, a new metal-free semiconductor graphic carbon nitride $\left(\mathrm{g}-\mathrm{C}_{3} \mathrm{~N}_{4}\right)$ has been identified as a potential photocatalyst under visible-light illumination ${ }^{2,3}$ for various processes including hydrogen evolution from water splitting, ${ }^{4} \mathrm{CO}_{2}$ reduction into hydrocarbon fuels, ${ }^{5}$ organic compounds degradation, ${ }^{6}$ and so on. The reason for the popularity of $g-\mathrm{C}_{3} \mathrm{~N}_{4}$ among many scholars is its high chemical stability and appealing electronic structure. ${ }^{7,8}$ The band gap of $\mathrm{g}-\mathrm{C}_{3} \mathrm{~N}_{4}$ is approximately $2.70 \mathrm{eV}$ with a valence band and conduction band at +1.60 and $-1.10 \mathrm{eV}$, respectively. ${ }^{9}$ It is in fact a graphitelike layered material with weak van der Waals forces between layers. ${ }^{10}$ However, bulk g- $\mathrm{C}_{3} \mathrm{~N}_{4}$ obtained using thermal polycondensation shows heavy agglomeration, which is adverse for photocatalytic applications.

Many methods, such as photocatalyst coupling, ${ }^{\mathbf{1 1}, 12}$ elemental doping, ${ }^{13-15}$ morphology control, ${ }^{16,17}$ and exfoliation, ${ }^{18-21}$ have

${ }^{a}$ School of Materials Science and Engineering, Hefei University of Technology, Hefei 230009, China. E-mail: gqxu1979@hfut.edu.cn; ycwu@hfut.edu.cn; Tel: +86551 62901372

${ }^{b}$ Industry \& Equipment Technology, Institute of Hefei University of Technology, Hefei 230009, China

'Key Laboratory of Advanced Functional Materials and Devices of Anhui Province, Hefei University of Technology, Hefei 230009, China been used for enhancing the photocatalytic performance of $\mathrm{g}$ $\mathrm{C}_{3} \mathrm{~N}_{4}$. Inspired by the huge success of graphene exfoliated from bulk graphite, the rational extension of the graphene strategy to layered $g-\mathrm{C}_{3} \mathrm{~N}_{4}$ is possible. Zhang et al. reported the preparation of $\mathrm{g}-\mathrm{C}_{3} \mathrm{~N}_{4}$ nanosheets using water as a solvent during ultrasonication. The nanosheets with a thickness of $2.5 \mathrm{~nm}$ showed extremely high PL quantum yield of up to $19.6 \% .{ }^{22}$ Sano et al. treated melamine-derived $\mathrm{g}-\mathrm{C}_{3} \mathrm{~N}_{4}$ with a $\mathrm{NaOH}$ solution. The grain size of the treated $\mathrm{g}-\mathrm{C}_{3} \mathrm{~N}_{4}$ was significantly reduced along with the formation of a mesoporous structure, and the surface area was enlarged from $c a .8$ to $65 \mathrm{~m}^{2} \mathrm{~g}^{-1} \cdot{ }^{23}$ Zhao et al. combined the thermal exfoliation method with sonication process in organic solvents that resulted in single-atomic-layer $g-\mathrm{C}_{3} \mathrm{~N}_{4}$ nanosheets with higher photocurrent and lower charge-transfer resistance as compared to bulk g- $\mathrm{C}_{3} \mathrm{~N}_{4}{ }^{24,25}$ However, there are many deficiencies in these stripping methods, for instance, the small yield of $\mathrm{g}-\mathrm{C}_{3} \mathrm{~N}_{4}$ nanosheets, complex experimental methodology, and long experimental period.

Herein, we present $\mathrm{g}-\mathrm{C}_{3} \mathrm{~N}_{4}$ nanosheets fabricated by an easy and environmentally friendly method of liquid stripping in an ammonia solution; this method is believed to be an efficient way for developing $\mathrm{g}-\mathrm{C}_{3} \mathrm{~N}_{4}$ nanosheets as photocatalysts for environmental remediation.

\section{Experimental}

\subsection{Chemicals and instruments}

Melamine $\left(\mathrm{C}_{3} \mathrm{H}_{6} \mathrm{~N}_{6}\right)$, ammonia water $\left(\mathrm{NH}_{3} \cdot \mathrm{H}_{2} \mathrm{O}\right)$, ethyl alcohol $\left(\mathrm{C}_{2} \mathrm{H}_{6} \mathrm{O}\right)$, and rhodamine $\mathrm{B}(\mathrm{RhB})$ were purchased from 
Sinopharm Chemical Reagent company. All reagents are analytical reagent (AR) and used without further purification.

An X-ray diffractometer (D/MAX2500 V) with $\mathrm{Cu} \mathrm{K \alpha}$ radiation was used to measure the phase structures of the samples, and the range of $2 \theta$ was from $5^{\circ}$ to $90^{\circ}$. A JEM-2100F high-resolution transmission electron microscope was used to observe the morphologies of the samples. An ESCALAB 250 photoelectron spectrometer with a monochromatic Al K $\alpha$ X-ray beam $(1486.60$ $\mathrm{eV)}$ was used for elemental analysis. An FTIR spectrometer (Nicolet 6700) was used to investigate the functional groups of the samples. Raman spectroscopy of the samples was conducted using an HR Evolution spectrometer with a $785 \mathrm{~nm}$ laser; a diffuse reflectance spectrometer (UV3600, Shimadzu) with $\mathrm{BaSO}_{4}$ as the reference was used to investigate the optical absorption performance of the samples.

Photocatalytic tests were completed using an XPA-7 photochemical reactor (Nanjing Xujiang Machine-electronic Company, China). A $250 \mathrm{~W}$ metal halide lamp with UV light filters removing light shorter than $420 \mathrm{~nm}$ was used as the visible-light source.

\subsection{Synthesis}

Bulk $\mathrm{g}-\mathrm{C}_{3} \mathrm{~N}_{4}$ was synthesized by heating melamine in a muffle furnace (OTF-1200X) at $550{ }^{\circ} \mathrm{C}$ for $4 \mathrm{~h}$ at a heating rate of $8{ }^{\circ} \mathrm{C}$ $\min ^{-1}$. A luminous yellow product was obtained and defined as bulk g- $\mathrm{C}_{3} \mathrm{~N}_{4}$.

The stripping of $\mathrm{g}-\mathrm{C}_{3} \mathrm{~N}_{4}$ was conducted by treating the bulk $\mathrm{g}$ $\mathrm{C}_{3} \mathrm{~N}_{4}$ in an ammonia solution at different temperatures, and a schematic of the process is shown in Fig. 1. Briefly, $200 \mathrm{mg}$ of bulk g- $\mathrm{C}_{3} \mathrm{~N}_{4}$ was dispersed in $25 \mathrm{~mL}$ of ammonia solution and the dispersion was placed in a Teflon-lined high pressure reaction kettle. Then, the reaction kettle was sealed and placed in an oven at a certain temperature for $8 \mathrm{~h}$. Finally, the $\mathrm{g}-\mathrm{C}_{3} \mathrm{~N}_{4}$ nanosheets were obtained via centrifuging and rinsing the suspension. The $\mathrm{g}-\mathrm{C}_{3} \mathrm{~N}_{4}$ nanosheets obtained at various temperatures of $30,60,80$, and $100{ }^{\circ} \mathrm{C}$ were defined as $\mathrm{g}-\mathrm{C}_{3} \mathrm{~N}_{4}$ (30), g- $\mathrm{C}_{3} \mathrm{~N}_{4}$ (60), g- $\mathrm{C}_{3} \mathrm{~N}_{4}$ (80), and $\mathrm{g}-\mathrm{C}_{3} \mathrm{~N}_{4}$ (100) nanosheets, respectively.

\subsection{Photocatalytic properties}

Rhodamine $\mathrm{B}(\mathrm{RhB})$ was used to evaluate the photocatalytic performance of the $\mathrm{g}-\mathrm{C}_{3} \mathrm{~N}_{4}$ nanosheets. In a typical procedure, $10 \mathrm{mg}$ photocatalysts were dispersed in $10 \mathrm{~mL}$ of RhB solution at a concentration of $10 \mathrm{mg} \mathrm{L}^{-1}$. The suspension was vigorously stirred for $30 \mathrm{~min}$ to achieve an adsorption/desorption equilibrium in the dark. A $250 \mathrm{~W}$ metal halide lamp with UV light filters $(420 \mathrm{~nm})$ was used as the visible-light source. An XPA-7 photochemical reactor was used for the photocatalytic reactions. The distance between the solution and the lamp was $10 \mathrm{~cm}$. Every $30 \mathrm{~min}$, a test tube was taken out, and the suspended liquid was centrifuged. Then, a UV1800 spectrometer was used to measure the clear solution, and the remaining concentration of RhB could be obtained.

\section{Results and discussion}

\subsection{Characterization}

Fig. 2 shows the X-ray diffraction (XRD) patterns of bulk g- $\mathrm{C}_{3} \mathrm{~N}_{4}$ and the $\mathrm{g}-\mathrm{C}_{3} \mathrm{~N}_{4}$ nanosheets obtained at different temperatures. Herein, two typical diffraction peaks were observed in all the samples. The strong peak at $27.83^{\circ}$ can be indexed as the diffraction peak of the (002) lattice plane, originating from the characteristic interlayer periodic stacking along the $c$-axis in graphitic carbon nitride. ${ }^{26}$ The weak diffraction peak at $12.94^{\circ}$ corresponds to the (100) lattice plane of $\mathrm{g}-\mathrm{C}_{3} \mathrm{~N}_{4}$ with a plane spacing of $0.680 \mathrm{~nm}$, corresponding to the in-plane structural packing motif or the heptazine units.

When compared with those of bulk $\mathrm{g}-\mathrm{C}_{3} \mathrm{~N}_{4}$, the diffraction peak positions of all $\mathrm{g}-\mathrm{C}_{3} \mathrm{~N}_{4}$ nanosheets are almost the same, indicating the same interplanar spacing of the (002) planes. Apparently, the (002) diffraction peaks are in good agreement with those of the previously reported $\mathrm{g}-\mathrm{C}_{3} \mathrm{~N}_{4} ;{ }^{27}$ this indicates

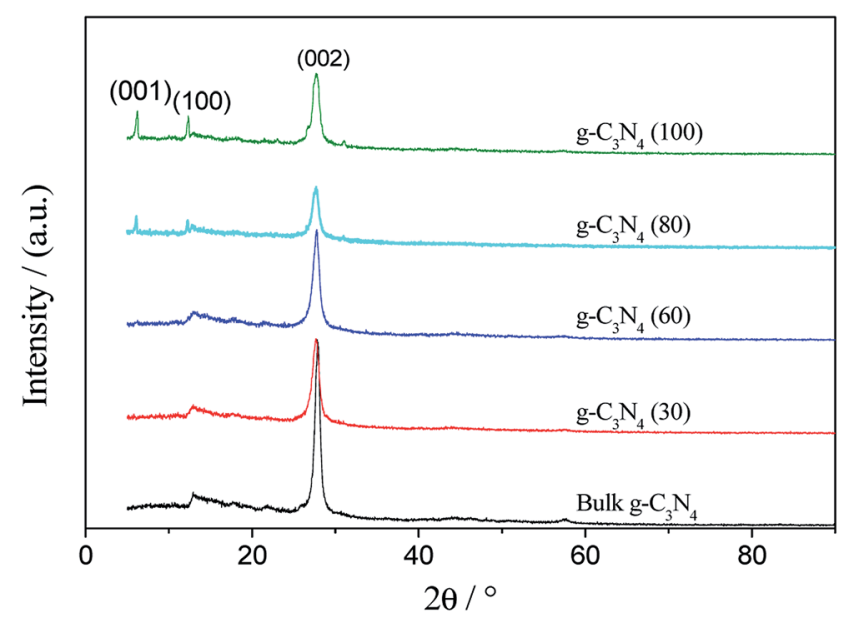

Fig. 2 The XRD patterns of bulk $\mathrm{g}-\mathrm{C}_{3} \mathrm{~N}_{4}$ and the $\mathrm{g}-\mathrm{C}_{3} \mathrm{~N}_{4}$ nanosheets prepared at different temperatures.
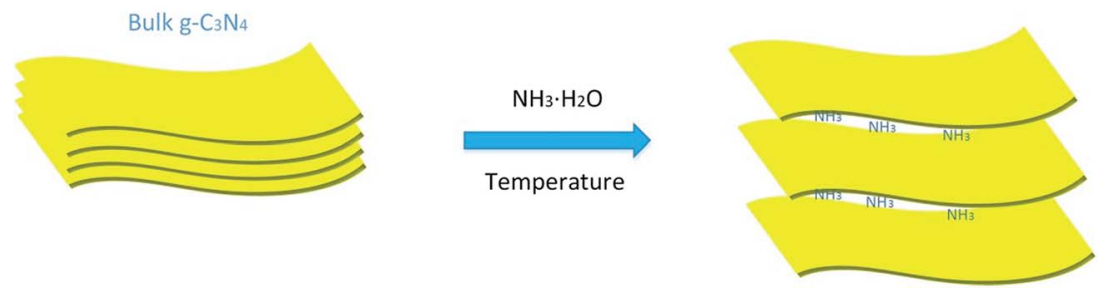

Fig. 1 A schematic of the synthesis of the $\mathrm{g}-\mathrm{C}_{3} \mathrm{~N}_{4}$ nanosheets. 
that the g- $\mathrm{C}_{3} \mathrm{~N}_{4}$ nanosheets still retain a layered structure after being treated with the ammonia solution. In addition, the intensity of the (002) peak significantly decreases after liquid stripping; this demonstrates the thin layer of $\mathrm{g}-\mathrm{C}_{3} \mathrm{~N}_{4}$ nanosheets with short periodicity.

The $\mathrm{g}-\mathrm{C}_{3} \mathrm{~N}_{4}$ nanosheets show a new diffraction peak at $6.22^{\circ}$ when the temperature is $60{ }^{\circ} \mathrm{C}$; this peak may be attributed to the (001) lattice plane with the d-spacing of $1.421 \mathrm{~nm} .{ }^{28}$ The peak intensity increases with temperature ranging from 60 to $100{ }^{\circ} \mathrm{C}$. Especially, the narrow peaks of the (001) and (100) lattice planes in the $\mathrm{g}-\mathrm{C}_{3} \mathrm{~N}_{4}$ (100) nanosheets indicate the good crystallization of this product.

The morphologies of bulk g- $\mathrm{C}_{3} \mathrm{~N}_{4}$ and the g- $\mathrm{C}_{3} \mathrm{~N}_{4}$ nanosheets were observed by transmission electron microscopy (TEM), as shown in Fig. 3. Fig. 3(i) shows the morphology of bulk g- $\mathrm{C}_{3} \mathrm{~N}_{4}$ without further treatment. Only large agglomerates with the sizes of several micrometers can be observed in the TEM images of bulk g- $\mathrm{C}_{3} \mathrm{~N}_{4}$.

The morphologies of the liquid stripping products obtained at different temperatures are shown in Fig. 3(ii)-(v). The g- $\mathrm{C}_{3} \mathrm{~N}_{4}$ (30) and $\mathrm{g}-\mathrm{C}_{3} \mathrm{~N}_{4}(60)$ nanosheets show similar morphologies as the bulk $\mathrm{g}-\mathrm{C}_{3} \mathrm{~N}_{4}$. However, the stripping traces of the nanosheets on the large agglomerates can be observed, as shown in Fig. 3(ii) and (iii). The morphologies of $\mathrm{g}-\mathrm{C}_{3} \mathrm{~N}_{4}$ (80) and the $\mathrm{g}-\mathrm{C}_{3} \mathrm{~N}_{4}$ (100) nanosheets significantly changed, as shown in Fig. 3(iv) and (v). The nanosheets with the sizes of several hundred nanometers were observed in the $\mathrm{g}-\mathrm{C}_{3} \mathrm{~N}_{4}$ (80) sample. The thickness of the nanosheets is difficult to determine because the nanosheets are lying flat. Many rise-like nanoparticles can be observed in the $\mathrm{g}-\mathrm{C}_{3} \mathrm{~N}_{4}$ (100) sample, which are assembled from fine $\mathrm{g}-\mathrm{C}_{3} \mathrm{~N}_{4}$ nanosheets.

The elemental compositions of different samples were analyzed by XPS, as shown in Fig. 4. Fig. 4(i) shows the survey patterns of bulk g- $\mathrm{C}_{3} \mathrm{~N}_{4}$ and the g- $\mathrm{C}_{3} \mathrm{~N}_{4}$ nanosheets, from which it can be seen that $\mathrm{g}-\mathrm{C}_{3} \mathrm{~N}_{4}$ is primarily composed of carbon and nitrogen. In addition, the peak intensities of the $\mathrm{g}-\mathrm{C}_{3} \mathrm{~N}_{4}$ nanosheets were significantly lower than that of bulk $\mathrm{g}-\mathrm{C}_{3} \mathrm{~N}_{4}$; this could be ascribed to the layered loose structure produced by the stripping process. To gain insight into the chemical bonds between the carbon and nitrogen elements in $\mathrm{g}-\mathrm{C}_{3} \mathrm{~N}_{4}$, the highresolution patterns of the $\mathrm{C} 1 \mathrm{~s}$ and $\mathrm{N}$ 1s spectra were further decomposed into Gaussian-Lorentzian peaks, respectively. Fig. 4(ii) shows the high-resolution patterns of $\mathrm{C} 1 \mathrm{~s}$, from which two peaks at $288.1 \mathrm{eV}$ and $284.7 \mathrm{eV}$ can be observed. The former
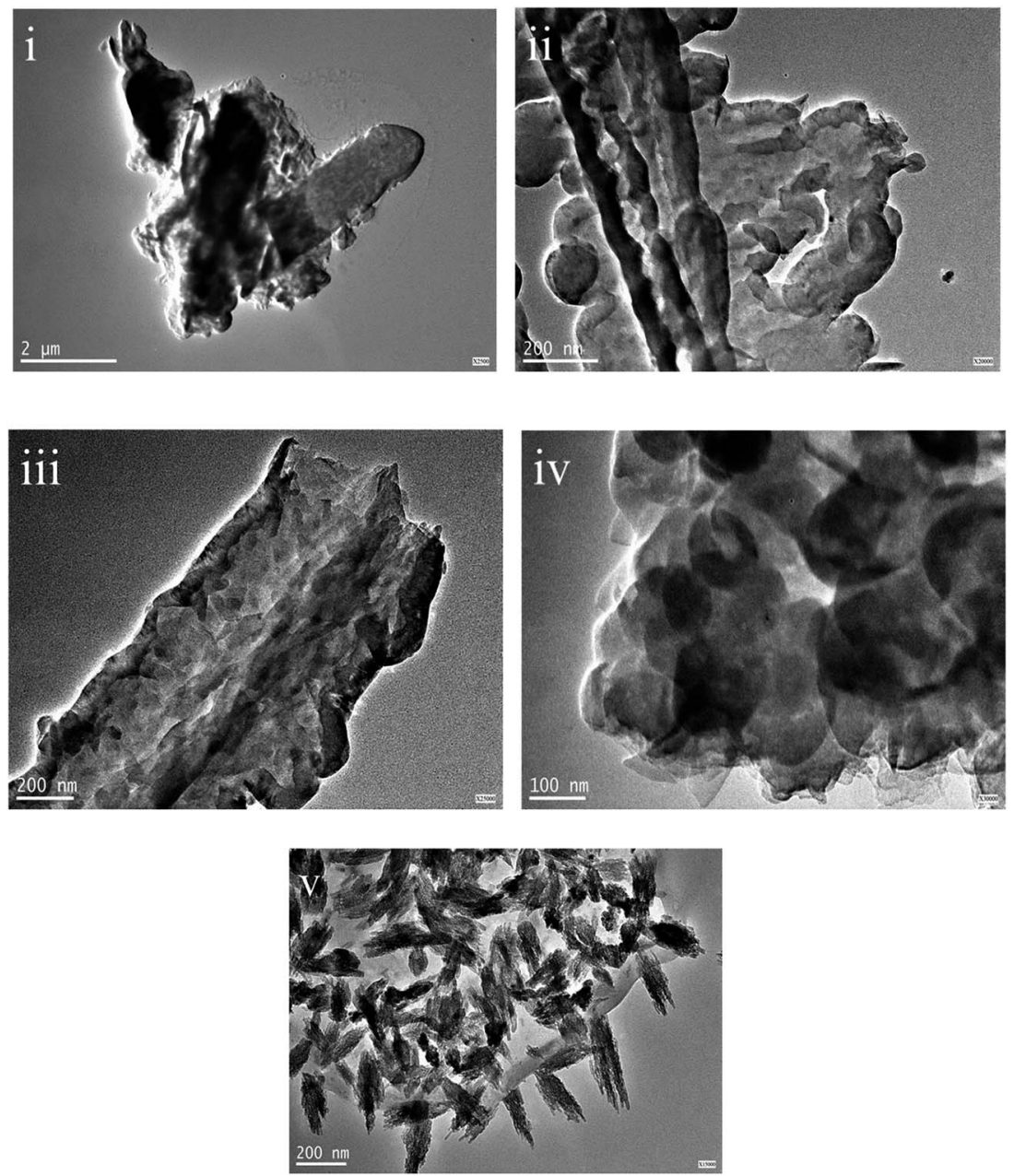

Fig. 3 The TEM morphologies of bulk g- $\mathrm{C}_{3} \mathrm{~N}_{4}$ (i) and the $\mathrm{g}-\mathrm{C}_{3} \mathrm{~N}_{4}$ nanosheets obtained at different temperatures of $30^{\circ} \mathrm{C}$ (ii), $60^{\circ} \mathrm{C}$ (iii), $80{ }^{\circ} \mathrm{C}$ (iv), and $100{ }^{\circ} \mathrm{C}(\mathrm{v})$. 

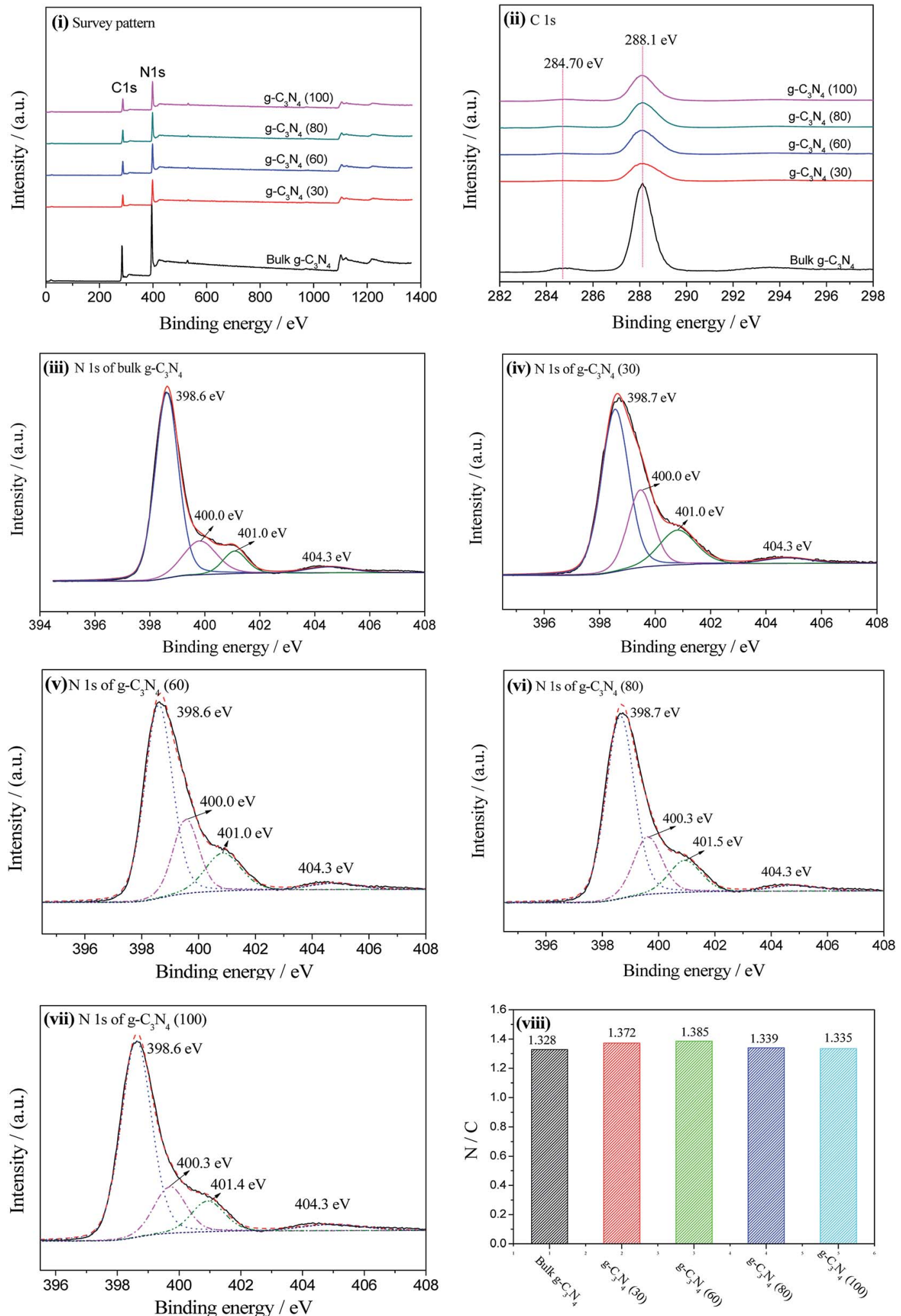

Fig. 4 The XPS patterns of bulk g- $\mathrm{C}_{3} \mathrm{~N}_{4}$ and the $\mathrm{g}-\mathrm{C}_{3} \mathrm{~N}_{4}$ nanosheets prepared at various temperatures: (i) survey pattern, (ii) high resolution pattern of $C 1 \mathrm{~s}$, (iii) $\mathrm{N}$ 1s of bulk g- $\mathrm{C}_{3} \mathrm{~N}_{4}$, (iv) $\mathrm{N}$ 1s of g- $\mathrm{C}_{3} \mathrm{~N}_{4}$ (30), (v) $\mathrm{N} 1 \mathrm{~s}$ of g- $\mathrm{C}_{3} \mathrm{~N}_{4}$ (60), (vi) $\mathrm{N} 1 \mathrm{~s}$ of g- $\mathrm{C}_{3} \mathrm{~N}_{4}(80)$, (vii) $\mathrm{N} 1 \mathrm{~s}$ of g- $\mathrm{C}_{3} \mathrm{~N}_{4}$ (100), and (viii) the $\mathrm{N} / \mathrm{C}$ ratios of the different samples.

can be assigned to the $\mathrm{sp}^{2}$-hybridized carbon in the $\mathrm{N}$ containing aromatic ring $(\mathrm{N}-\mathrm{C}=\mathrm{N}){ }^{29}$ which is the major aromatic carbon species in the polymeric $\mathrm{g}-\mathrm{C}_{3} \mathrm{~N}_{4}$. The latter is typically assigned to impurity of carbon such as $\mathrm{C}=\mathrm{C}$ or grease. Moreover, the high-resolution patterns of $\mathrm{N} 1 \mathrm{~s}$ were also decomposed into four different peaks with the binding energies 
at approximately 398.6, 400.0, 401.0, and $404.3 \mathrm{eV}$, respectively, as shown in Fig. 4(iii)-(vi), which could be assigned to the $\mathrm{sp}^{2}$ hybridized nitrogen involved in the tri-s-triazine ring $(\mathrm{C}-\mathrm{N}=\mathrm{C})$, the tertiary nitrogen $\mathrm{N}-(\mathrm{C})_{3}$ group, the hydrogen-bearing amine $\mathrm{C}-\mathrm{N}-\mathrm{H}$ group, and the charge effects or positive charge localization in the heterocycles, respectively. ${ }^{30}$

Table 1 is the peak information of $\mathrm{N} 1 \mathrm{~s}$ obtained from the Gaussian decomposition shown in Fig. 4(iii)-(vi), including the peak position, full width at half maximum (FWHM), and peak area and percentage.

Compared to those of bulk $\mathrm{g}-\mathrm{C}_{3} \mathrm{~N}_{4}$, the peak areas of the $\mathrm{g}$ $\mathrm{C}_{3} \mathrm{~N}_{4}$ nanosheets dramatically reduced, which well-matched with the intensity change observed in the XRD patterns. In addition, the FWHM of the $\mathrm{C}-\mathrm{N}-\mathrm{H}$ group and $\mathrm{N}-(\mathrm{C})_{3}$ group peaks in the $\mathrm{g}-\mathrm{C}_{3} \mathrm{~N}_{4}$ nanosheets are different from that of bulk $\mathrm{g}$ $\mathrm{C}_{3} \mathrm{~N}_{4}$; this may be ascribed to the $\mathrm{NH}_{3}$ molecules in the interlamination of $\mathrm{g}-\mathrm{C}_{3} \mathrm{~N}_{4}$ and the change in the $\mathrm{C}-\mathrm{N}-\mathrm{C}$ and $\mathrm{N}-(\mathrm{C})_{3}$ environment. ${ }^{31}$ Especially, the FWHMs of the $\mathrm{N}-(\mathrm{C})_{3}$ peak in the g- $\mathrm{C}_{3} \mathrm{~N}_{4}$ nanosheets are much wider than those found in bulk $\mathrm{g}$ $\mathrm{C}_{3} \mathrm{~N}_{4}$; this indicates that more tri-s-triazine in the bulk g- $\mathrm{C}_{3} \mathrm{~N}_{4}$ are separated after it is treated in an ammonia solution. The peak position of the $\mathrm{C}-\mathrm{N}-\mathrm{H}$ group in $\mathrm{g}-\mathrm{C}_{3} \mathrm{~N}_{4}(80)$ and the $\mathrm{g}-\mathrm{C}_{3} \mathrm{~N}_{4}$ (100) nanosheets slightly shifts towards higher energy, demonstrating that the electron density of the $\mathrm{N}$ atoms is reduced, which is a typical feature of the exfoliation process. ${ }^{32}$ Moreover, the increase in the $\mathrm{C}-\mathrm{N}-\mathrm{H}$ percentage from $8.96 \%$ in bulk $\mathrm{g}-\mathrm{C}_{3} \mathrm{~N}_{4}$ to $16.57 \%, 15.39 \%, 13.04 \%$, and $11.89 \%$ in the $\mathrm{g}$ $\mathrm{C}_{3} \mathrm{~N}_{4}$ nanosheets indicates the breakage of in-layers.

Fig. 4(viii) shows the N/C ratio of bulk g- $\mathrm{C}_{3} \mathrm{~N}_{4}$ and the $\mathrm{g}-\mathrm{C}_{3} \mathrm{~N}_{4}$ nanosheets, which are 1.328, 1.372, 1.385, 1.339, and 1.335. Apparently, the $\mathrm{N} / \mathrm{C}$ ratio of the $\mathrm{g}-\mathrm{C}_{3} \mathrm{~N}_{4}$ nanosheets was close to the $\mathrm{N} / \mathrm{C}$ ratio of bulk $\mathrm{g}-\mathrm{C}_{3} \mathrm{~N}_{4}$; this indicated that the chemical composition and the coordination of carbon and nitride in the g- $\mathrm{C}_{3} \mathrm{~N}_{4}$ nanosheets were retained during the liquid exfoliation process. ${ }^{33}$ However, higher N/C ratios of $\mathrm{g}-\mathrm{C}_{3} \mathrm{~N}_{4}$ (30) and $\mathrm{g}-\mathrm{C}_{3} \mathrm{~N}_{4}$ (60) than those found in bulk $\mathrm{g}-\mathrm{C}_{3} \mathrm{~N}_{4}$ may be ascribed to the adsorption of $\mathrm{NH}_{3}$ molecules in the interlayers of the $\mathrm{g}-\mathrm{C}_{3} \mathrm{~N}_{4}$ nanosheets, leading to the lattice expansion and exfoliation of the nanosheets.

Fig. 5 shows the Raman spectra of bulk $\mathrm{g}-\mathrm{C}_{3} \mathrm{~N}_{4}$ and the $\mathrm{g}$ $\mathrm{C}_{3} \mathrm{~N}_{4}$ nanosheets obtained at various temperatures. The characteristic peaks of $\mathrm{g}-\mathrm{C}_{3} \mathrm{~N}_{4}$ agree well with that reported in literature. ${ }^{34}$ Moreover, all the Raman bands observed for bulk g$\mathrm{C}_{3} \mathrm{~N}_{4}$ can be found in the $\mathrm{g}-\mathrm{C}_{3} \mathrm{~N}_{4}$ nanosheets; this confirms that the main structure of the $\mathrm{g}-\mathrm{C}_{3} \mathrm{~N}_{4}$ nanosheets is not destroyed. In addition, the intensities of the peaks at $590 \mathrm{~cm}^{-1}, 707 \mathrm{~cm}^{-1}$, $767 \mathrm{~cm}^{-1}, 1233 \mathrm{~cm}^{-1}$, and $1311 \mathrm{~cm}^{-1}$ in the $\mathrm{g}-\mathrm{C}_{3} \mathrm{~N}_{4}$ nanosheets decrease as compared to those of bulk g- $\mathrm{C}_{3} \mathrm{~N}_{4}$; this can be attributed to the effect of the liquid stripping process.

The chemical structures of bulk $\mathrm{g}-\mathrm{C}_{3} \mathrm{~N}_{4}$ and the $\mathrm{g}-\mathrm{C}_{3} \mathrm{~N}_{4}$ nanosheets were further investigated using the FTIR spectra, as shown in Fig. 6. An absorption band in the region from 1000 to $1750 \mathrm{~cm}^{-1}$ and a peak at $890 \mathrm{~cm}^{-1}$ are the characteristic absorptions for the stretching and bending modes of $\mathrm{N}$-containing heterocycles, respectively. ${ }^{35}$ The broad peak at

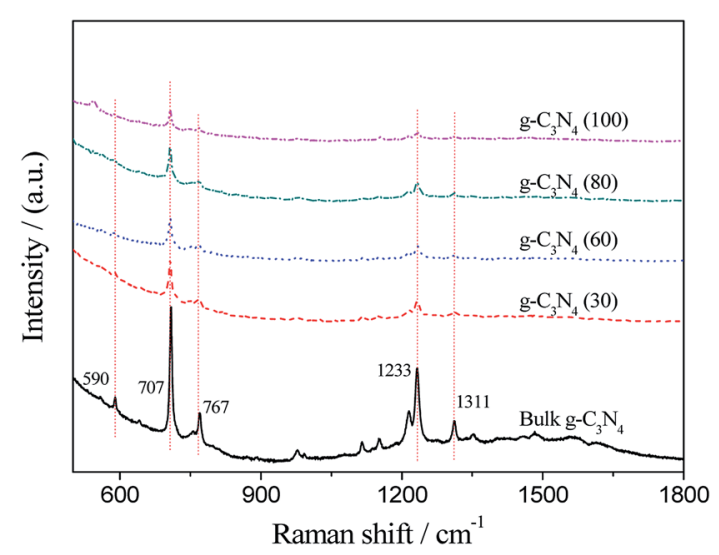

Fig. 5 The Raman spectra of bulk g- $\mathrm{C}_{3} \mathrm{~N}_{4}$ and the $\mathrm{g}-\mathrm{C}_{3} \mathrm{~N}_{4}$ nanosheets obtained at various temperatures.

Table 1 The peak parameters of $\mathrm{N}$ 1s in different samples

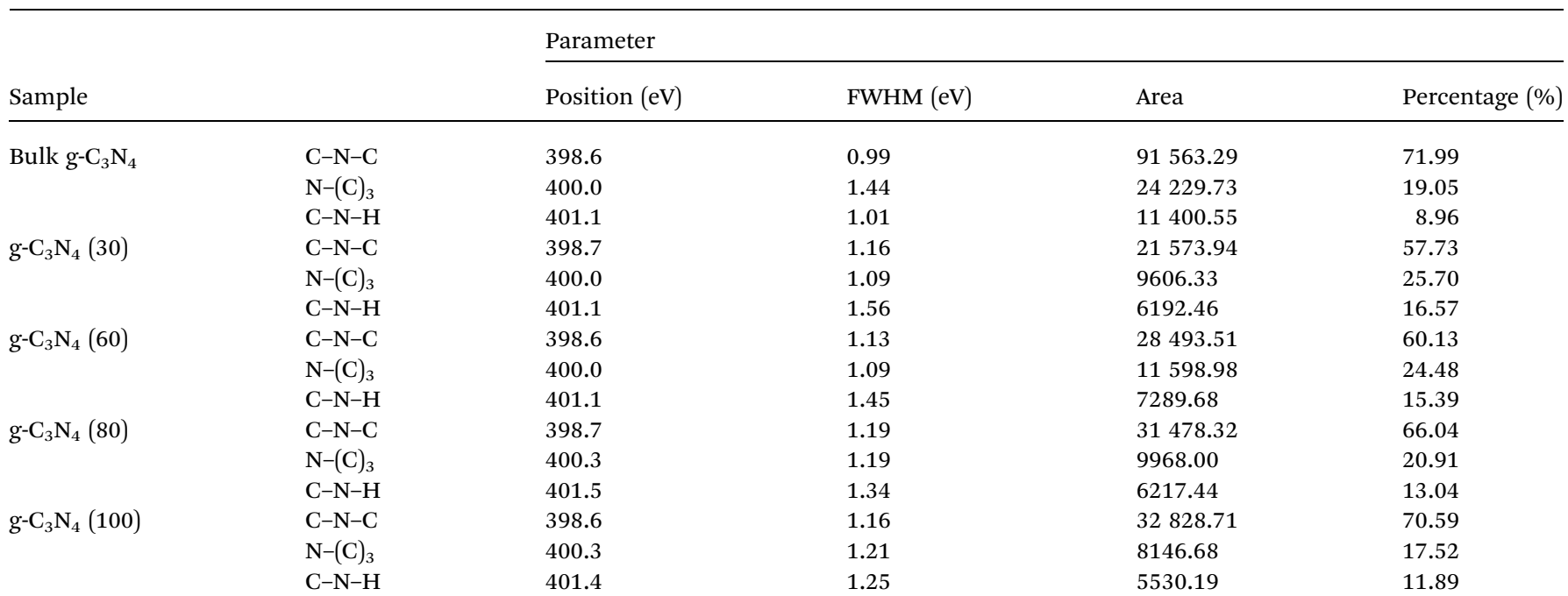



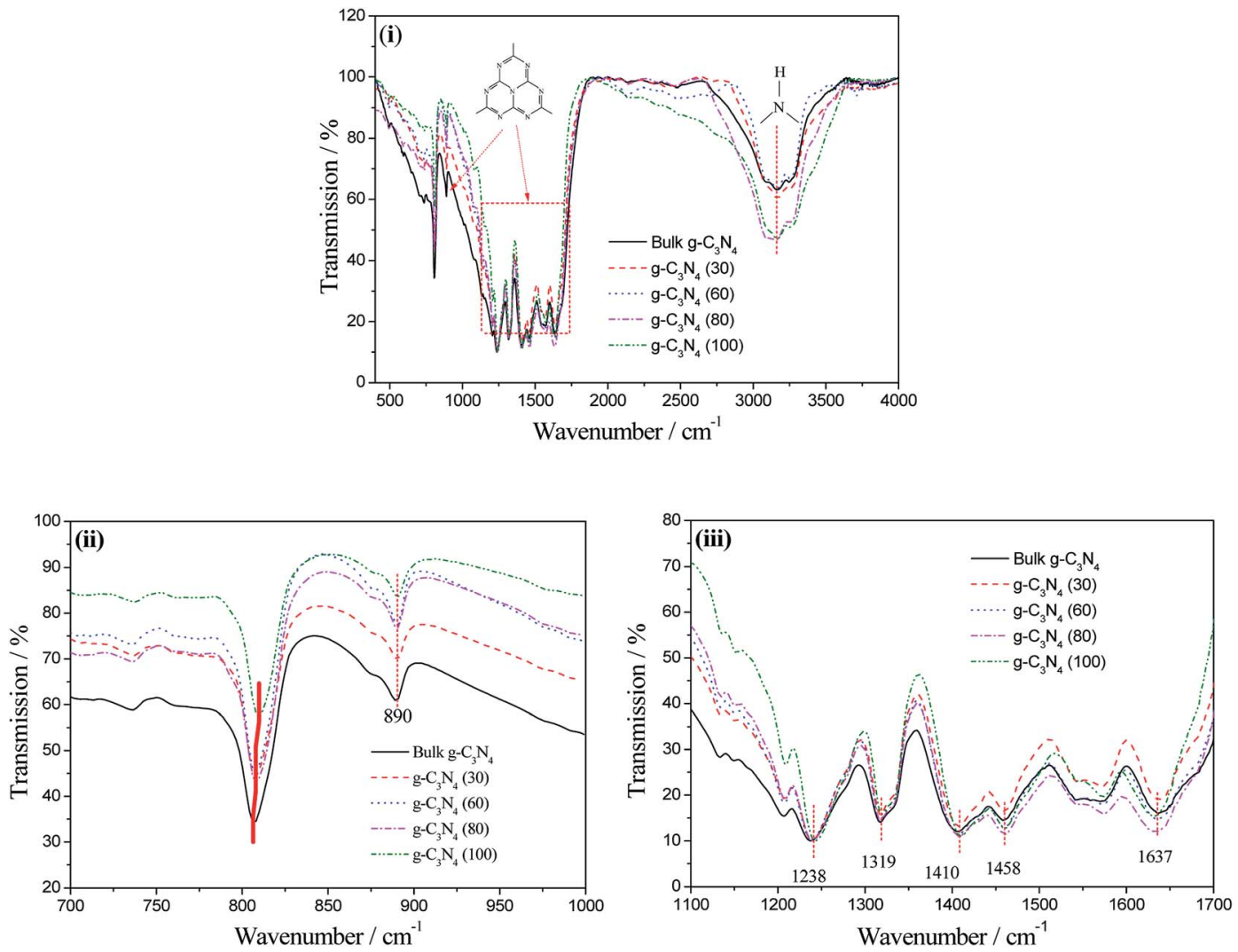

Fig. 6 The FTIR spectra of bulk $\mathrm{g}-\mathrm{C}_{3} \mathrm{~N}_{4}$ and the $\mathrm{g}-\mathrm{C}_{3} \mathrm{~N}_{4}$ nanosheets prepared at various temperatures.

approximately $3200 \mathrm{~cm}^{-1}$ was related to the $\mathrm{N}-\mathrm{H}$ stretching associated with the hydrogenation of $\mathrm{sp}^{2}-\mathrm{N} .^{36-38}$ The detailed information is shown in Fig. 6(ii) and (iii). In Fig. 6(ii), the signals at approximately $808 \mathrm{~cm}^{-1}$ can be attributed to ringsextant out-of-plane bending vibration of the triazine or heptazine units. ${ }^{39}$ Clearly, this peak of the $\mathrm{g}-\mathrm{C}_{3} \mathrm{~N}_{4}$ (100) nanosheets slightly shifts towards higher wavenumber; this is evidence of the exfoliation effect. In Fig. 6(iii), the peaks at $1238,1319,1458$, and $1637 \mathrm{~cm}^{-1}$ can be attributed to the skeletal vibrations of the heptazine heterocyclic ring $\left(\mathrm{C}_{6} \mathrm{~N}_{7}\right)$ units. In addition, the peak at $1410 \mathrm{~cm}^{-1}$ is a characteristic absorption peak for the stretching vibrations of the s-triazine ring $\left(\mathrm{C}_{3} \mathrm{~N}_{3}\right)$ units. On combining the results of XPS and FTIR analyses, it can be confirmed that the extracted nanosheets are in fairly good accordance with the recent reports of $\mathrm{g}-\mathrm{C}_{3} \mathrm{~N}_{4}$ materials prepared via polycondensation reactions. ${ }^{40}$

\subsection{Photocatalytic performance}

The optical absorption and photoluminescence patterns of bulk ${ }^{g}-\mathrm{C}_{3} \mathrm{~N}_{4}$ and the g- $\mathrm{C}_{3} \mathrm{~N}_{4}$ nanosheets obtained at different temperatures are shown in Fig. 7. As shown in Fig. 7(i), two absorption peaks at $366 \mathrm{~nm}$ and $270 \mathrm{~nm}$ were obtained for bulk g- $\mathrm{C}_{3} \mathrm{~N}_{4}$. The g- $\mathrm{C}_{3} \mathrm{~N}_{4}$ nanosheets obtained at different temperatures show similar absorption bands with double peaks at $366 \mathrm{~nm}$ and $270 \mathrm{~nm}$ with a slight decrease in the absorption intensity.
The photoluminescence patterns of bulk g- $\mathrm{C}_{3} \mathrm{~N}_{4}$ and the g$\mathrm{C}_{3} \mathrm{~N}_{4}$ nanosheets under the excitation of $315 \mathrm{~nm}$ UV light are shown in Fig. 7(ii). All the samples possess the same emission peak at approximately $458 \mathrm{~nm}$, originating from the deficiencies in $\mathrm{g}-\mathrm{C}_{3} \mathrm{~N}_{4}$. The intensities of the $\mathrm{g}-\mathrm{C}_{3} \mathrm{~N}_{4}$ nanosheets, particularly, those of the $\mathrm{g}-\mathrm{C}_{3} \mathrm{~N}_{4}(60)$ and $\mathrm{g}-\mathrm{C}_{3} \mathrm{~N}_{4}$ (80) nanosheets, prepared at various temperatures are higher than those of bulk $\mathrm{g}^{-} \mathrm{C}_{3} \mathrm{~N}_{4}$, indicating more structural deficiencies in the exfoliated g- $\mathrm{C}_{3} \mathrm{~N}_{4}$ nanosheets.

The photocatalytic performance was evaluated via $\mathrm{RhB}$ degradation, as shown in Fig. 8. Fig. 8(i) shows the plots of RhB degradation rate $v s$. time. The initial $30 \mathrm{~min}$ shows the adsorption rate of $\mathrm{RhB}$ in dark. Bulk g- $\mathrm{C}_{3} \mathrm{~N}_{4}$ shows an adsorption ratio of approximately $5 \%$ in $30 \mathrm{~min}$, higher than that of the P25 powder (1.2\% in $30 \mathrm{~min})$. All the $\mathrm{g}-\mathrm{C}_{3} \mathrm{~N}_{4}$ nanosheets show a higher adsorption rate than bulk g- $\mathrm{C}_{3} \mathrm{~N}_{4}$. The g- $\mathrm{C}_{3} \mathrm{~N}_{4}$ nanosheets obtained at $80{ }^{\circ} \mathrm{C}$ and $100{ }^{\circ} \mathrm{C}$ achieve a similar and highest adsorption ratio of $\sim 12 \%$.

Bulk $\mathrm{g}-\mathrm{C}_{3} \mathrm{~N}_{4}$ possesses poor photocatalytic performance in the decomposition of $\mathrm{RhB}$ due to low surface area. After illumination with visible-light for $120 \mathrm{~min}$, only $27.7 \%$ (containing $5 \%$ adsorption) of $\mathrm{RhB}$ was decomposed in the presence of bulk $\mathrm{g}^{-} \mathrm{C}_{3} \mathrm{~N}_{4}$, whereas for $\mathrm{P} 25$ powder, the decomposition ratio was approximately $58 \%$. All the g- $\mathrm{C}_{3} \mathrm{~N}_{4}$ nanosheets possess higher photodegradation rates than bulk g- $\mathrm{C}_{3} \mathrm{~N}_{4}$. In addition, most of the g- $\mathrm{C}_{3} \mathrm{~N}_{4}$ nanosheets can completely degrade $\mathrm{RhB}$ in $120 \mathrm{~min}$. Although the $\mathrm{g}-\mathrm{C}_{3} \mathrm{~N}_{4}$ nanosheets obtained at various 

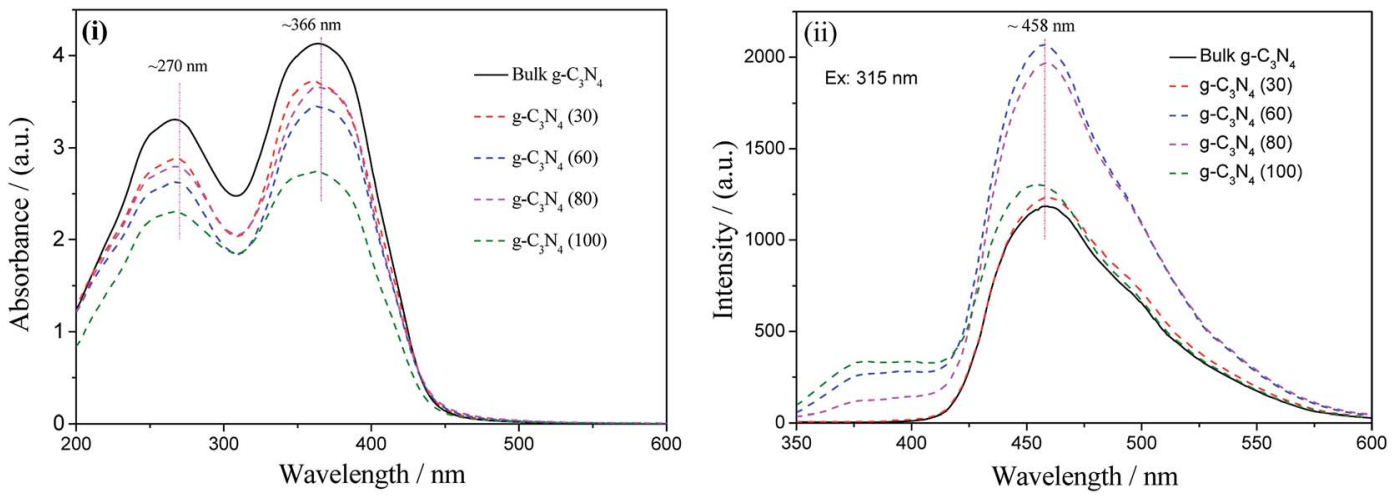

Fig. 7 The optical absorption (i) and photoluminescence (ii) spectra of bulk $\mathrm{g}-\mathrm{C}_{3} \mathrm{~N}_{4}$ and the $\mathrm{g}-\mathrm{C}_{3} \mathrm{~N}_{4}$ nanosheets prepared at various temperatures.
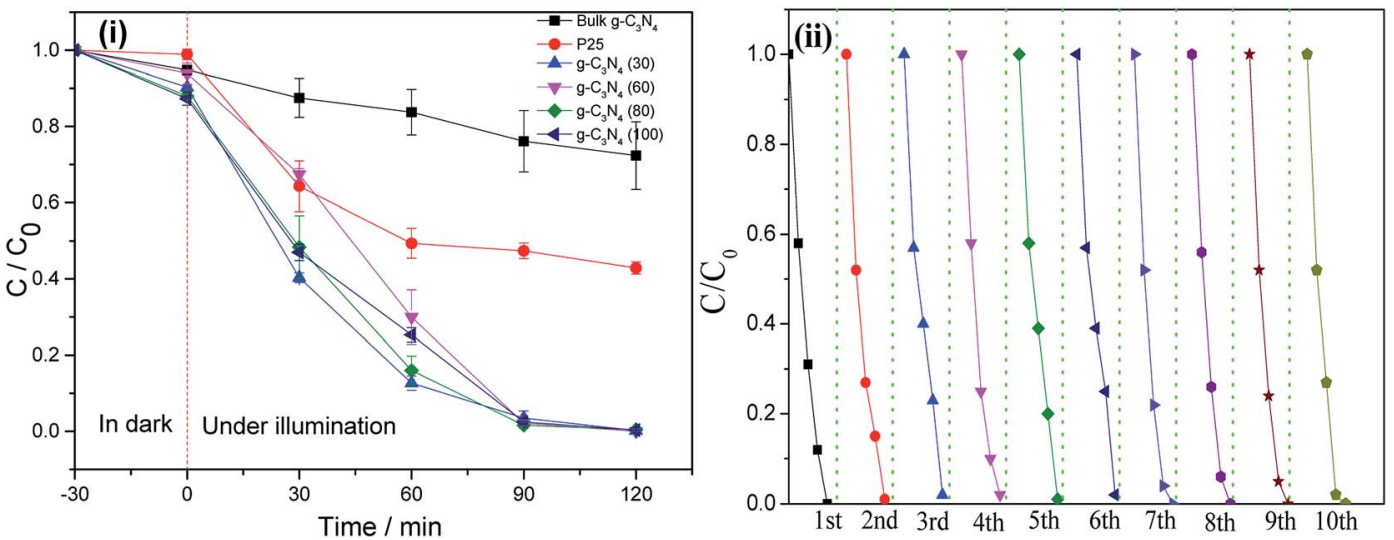

Fig. 8 The photocatalytic performance of bulk g- $C_{3} N_{4}$ and the $g-C_{3} N_{4}$ nanosheets prepared at various temperatures under visible-light illumination. (i) The degradation rate of RhB vs. time and (ii) the recyclability test of the $\mathrm{g}-\mathrm{C}_{3} \mathrm{~N}_{4}(100)$ nanosheets.

temperatures show similar degradation rates in 90 and $120 \mathrm{~min}$, the difference in the degradation velocity among the $\mathrm{g}-\mathrm{C}_{3} \mathrm{~N}_{4}$ nanosheets can be observed at a degradation time of $30 \mathrm{~min}$. The $\mathrm{g}^{-} \mathrm{C}_{3} \mathrm{~N}_{4}$ (30) nanosheets achieve the highest degradation ratio of $60 \%$ in 30 min under visible-light illumination. The increase in temperature slightly decreases the degradation rate to $55 \%$ in the $\mathrm{g}-\mathrm{C}_{3} \mathrm{~N}_{4}(80)$ and $\mathrm{g}-\mathrm{C}_{3} \mathrm{~N}_{4}(100)$ nanosheets.

Fig. 8(ii) shows the plots for RhB degradation when the g$\mathrm{C}_{3} \mathrm{~N}_{4}$ (100) nanosheets are reused for 10 cycles under the same conditions. In the first cycle, RhB can be completely degraded at $120 \mathrm{~min}$. When the photocatalytic process was further repeated 10 times, the photocatalyst retained the same degradation ability, indicating excellent recyclability of the $\mathrm{g}^{-} \mathrm{C}_{3} \mathrm{~N}_{4}$ nanosheets under visible-light illumination.

\subsection{Mechanism discussion}

$\mathrm{g}^{-} \mathrm{C}_{3} \mathrm{~N}_{4}$ can be exfoliated in an ammonia solution at various temperatures, leading to an increase in the visible-light photocatalytic activity. The optical absorption, surface adsorption, charger transfer, and surface catalytic reactions ${ }^{41}$ have been discussed to explain the change in the photocatalytic performance.
The optical absorption of the $\mathrm{g}-\mathrm{C}_{3} \mathrm{~N}_{4}$ nanosheets has been discussed in Fig. 7, which is the first step in the photocatalytic process. Clearly, the absorption edges of the g- $\mathrm{C}_{3} \mathrm{~N}_{4}$ nanosheets show a slight blue shift when compared with those of bulk g$\mathrm{C}_{3} \mathrm{~N}_{4}$; this is adverse for visible-light photocatalytic degradation. The blue-shift in the band edge and low adsorption intensity of the $\mathrm{g}-\mathrm{C}_{3} \mathrm{~N}_{4}$ nanosheets confirmed that the change in the optical absorption was not the factor responsible for enhancing the photocatalytic performance of $\mathrm{g}-\mathrm{C}_{3} \mathrm{~N}_{4}$ after it was treated in an ammonia solution.

Surface area is also a key factor influencing the photocatalytic performance. A higher surface area can supply more active sites for surface reactions, thereby enhancing the photocatalytic performance. The specific surface area of $\mathrm{g}-\mathrm{C}_{3} \mathrm{~N}_{4}$ (100) was measured to be $41.1 \mathrm{~m}^{2} \mathrm{~g}^{-1}$, which was much higher than that of bulk g- $\mathrm{C}_{3} \mathrm{~N}_{4}\left(15.2 \mathrm{~m}^{2} \mathrm{~g}^{-1}\right)$. The high specific surface area of the $\mathrm{g}-\mathrm{C}_{3} \mathrm{~N}_{4}$ nanosheets with a large number of deficiencies plays a key role in the photocatalytic degradation of RhB by providing more active sites.

A schematic of the photocatalytic process is shown in Fig. 9. When excited, the electrons in the valence band (VB) will move to the conduction band (CB), leading to the generation of the electron-hole pairs. On the surface of the photocatalyst, 


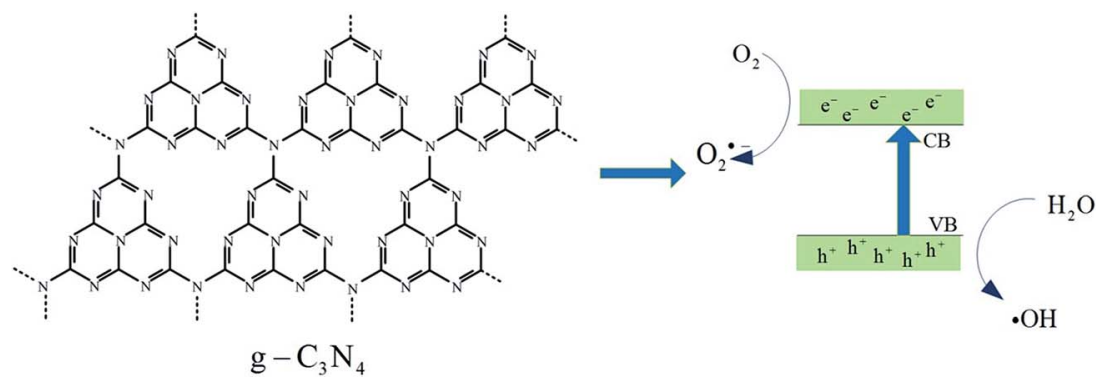

Fig. 9 A schematic of the photocatalytic process.

electrons combine with dissolved oxygen, generating superoxide anions $\left({ }^{\circ} \mathrm{O}_{2}^{-}\right)$, and the holes are captured by hydroxyl ions, generating hydroxyl free radicals $\left({ }^{\circ} \mathrm{OH}\right)$. Then, organic compounds will be oxidized by ${ }^{\circ} \mathrm{O}_{2}{ }^{-},{ }^{\circ} \mathrm{OH}$, and $\mathrm{h}^{+}$. Thus, ${ }^{\circ} \mathrm{O}_{2}{ }^{-}$, $\cdot \mathrm{OH}$, and $\mathrm{h}^{+}$are commonly considered as the main active species in the photocatalytic process. Herein, three sacrificial agents $\mathrm{NaI}$ for $\mathrm{h}^{+}$, BQ for ${ }^{\circ} \mathrm{O}_{2}^{-}$, and IPA for ${ }^{\circ} \mathrm{OH}$ were added to the $\mathrm{RhB}$ solution to study the main active species during the photocatalytic process.

The degradation rates of the RhB solution with the addition of different sacrificial agents for bulk g- $\mathrm{C}_{3} \mathrm{~N}_{4}$ and g- $\mathrm{C}_{3} \mathrm{~N}_{4}(30)$ are shown in Fig. 10. The degradation rates of bulk g- $\mathrm{C}_{3} \mathrm{~N}_{4}$ decrease from $40 \%$ to $12 \%$ and $25 \%$ with the addition of $\mathrm{NaI}$ and $\mathrm{BQ}$, which indicates that holes and ${ }^{\circ} \mathrm{O}_{2}{ }^{-}$radicals exist in the photocatalytic process. However, the degradation rate of bulk g$\mathrm{C}_{3} \mathrm{~N}_{4}$ slightly decreases from $40 \%$ to $38 \%$ with the addition of IPA, indicating that ${ }^{\circ} \mathrm{OH}$ radicals are not the main active species in the photodegradation process. Similarly, the changes in the degradation rate with the addition of sacrificial agents were measured for the g- $\mathrm{C}_{3} \mathrm{~N}_{4}$ nanosheets. NaI decreases the degradation rate from $99.5 \%$ to $60.7 \%$ and $\mathrm{BQ}$ decreases the degradation rate to $51.7 \%$. However, the degradation rates are still $99.3 \%$ when IPA is added to the RhB solution, indicating that hydroxyl free radicals are not the active species in the photocatalytic process of the $\mathrm{g}-\mathrm{C}_{3} \mathrm{~N}_{4}$ nanosheets and the exfoliation in ammonia solution does not change the surface reactions.

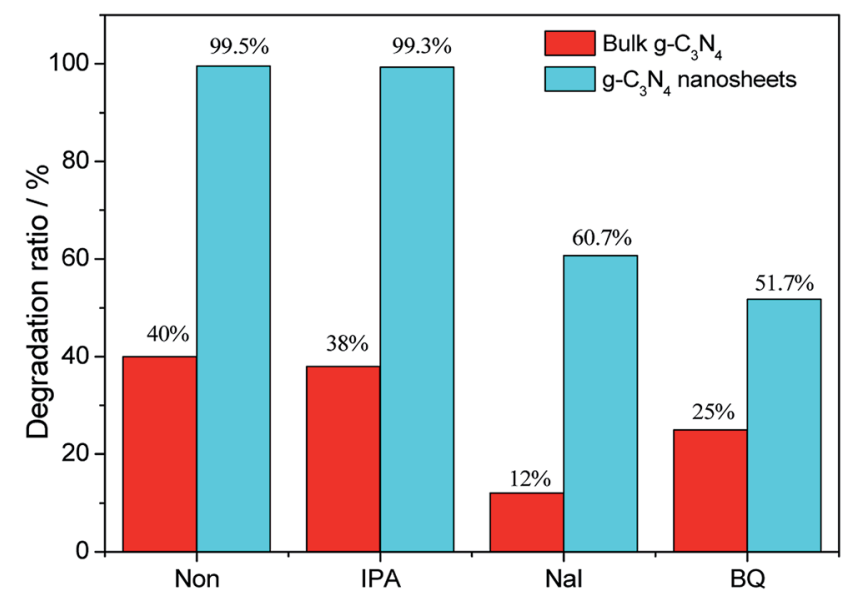

Fig. 10 The photocatalytic performance of bulk $\mathrm{g}-\mathrm{C}_{3} \mathrm{~N}_{4}$ and the $\mathrm{g}$ $\mathrm{C}_{3} \mathrm{~N}_{4}$ nanosheets towards $\mathrm{RhB}$ solutions upon adding $10 \mathrm{mM}$ of sacrificial agent including IPA, Nal and $B Q$.

\section{Conclusions}

Herein, g- $\mathrm{C}_{3} \mathrm{~N}_{4}$ nanosheets were obtained by exfoliating bulk g$\mathrm{C}_{3} \mathrm{~N}_{4}$ in an ammonia solution at various temperatures. The nanosheets with sizes of several hundred nanosheets can be obtained after liquid stripping in an ammonia solution. The photocatalytic performance of the g- $\mathrm{C}_{3} \mathrm{~N}_{4}$ nanosheets under visible-light illumination was significantly enhanced. All the exfoliated g- $\mathrm{C}_{3} \mathrm{~N}_{4}$ nanosheets can completely degrade $10 \mathrm{mg} \mathrm{L}^{-1}$ $\mathrm{RhB}$ in 120 min under visible-light illumination. In addition, the ${ }^{-}-\mathrm{C}_{3} \mathrm{~N}_{4}(30)$ nanosheets achieve the highest degradation rate of $88 \%$ in $60 \mathrm{~min}$, which is 5 times that of bulk $\mathrm{g}-\mathrm{C}_{3} \mathrm{~N}_{4}$. The enhancement in the photocatalytic performance under visiblelight illumination originates from the higher surface area with more active sites.

\section{Acknowledgements}

This work was supported by the Nature Science Foundation of China (51402078), Fundamental Research Funds for the Central Universities (2013HGQC0005), Nature Science Foundation of Anhui Province (1408085QE86), and Young Scholar Enhancement Foundation (Plan B) of HFUT, China (JZ2016HGTB0711).

\section{References}

1 G. Xu, H. Liu, J. Wang, J. Lv, Z. Zheng and Y. Wu, Electrochim. Acta, 2014, 121, 194-202.

2 M. Zhu, C. Zhai, L. Qiu, C. Lu, A. S. Paton, Y. Du and M. C. Goh, ACS Sustainable Chem. Eng., 2015, 3, 3123-3129.

3 J. Liu, H. Wang and M. Antonietti, Chem. Soc. Rev., 2016, 45, 2308-2326.

4 A. Indra, A. Acharjya, P. W. Menezes, C. Merschjann, D. Hollmann, M. Schwarze and M. Driess, Angew. Chem., 2017, 129, 1-6.

5 S. N. Habisreutinger, L. Schmidt-Mende and J. K. Stolarczyk, Angew. Chem., Int. Ed., 2013, 52, 7372-7408.

6 L. Sun, M. Yang, J. Huang, D. Yu, W. Hong and X. Chen, Adv. Funct. Mater., 2016, 26, 4943-4950.

7 Y. Wang, J. Zhang, X. Wang, M. Antonietti and H. Li, Angew. Chem., Int. Ed., 2010, 49, 3356-3359.

8 A. Thomas, A. Fischer, F. Goettmann, M. Antonietti, J. O. Müller, R. Schlögl and J. M. Carlsson, J. Mater. Chem., 2008, 18, 4893-4908. 
9 Y. Hou, A. B. Laursen, J. Zhang, G. Zhang, Y. Zhu, X. Wang and I. Chorkendorff, Angew. Chem., Int. Ed., 2013, 52, 36213625.

10 F. He, G. Chen, Y. Yu, S. Hao, Y. Zhou and Y. Zheng, ACS Appl. Mater. Interfaces, 2014, 6, 7171-7179.

11 L. Ge, C. Han, X. Xiao and L. Guo, Int. J. Hydrogen Energy, 2013, 38, 6960-6969.

12 S. C. Yan, Z. S. Li and Z. G. Zou, Langmuir, 2010, 26, 38943901.

13 E. Gottlieb, M. Kopeć, M. Banerjee, J. Mohin, D. Yaron, K. Matyjaszewski and T. Kowalewski, ACS Appl. Mater. Interfaces, 2016, 8, 21531-21538.

14 M. Zhu, C. Zhai, M. Sun, Y. Hu, B. Yan and Y. Du, Appl. Catal., B, 2017, 203, 108-115.

15 W. Ho, Z. Zhang, W. Lin, S. Huang, X. Zhang, X. Wang and Y. Huang, ACS Appl. Mater. Interfaces, 2015, 7, 5497-5505.

16 F. Dong, Z. Wang, Y. Li, W. K. Ho and S. C. Lee, Environ. Sci. Technol., 2014, 48, 10345-10353.

17 X. H. Li, X. Wang and M. Antonietti, ACS Catal., 2012, 2, 2082-2086.

18 Y. Lu, D. Chu, M. Zhu, Y. Du and P. Yang, Phys. Chem. Chem. Phys., 2015, 17, 17355-17361.

19 S. Yang, Y. Gong, J. Zhang, L. Zhan, L. Ma, Z. Fang and P. M. Ajayan, Adv. Mater., 2013, 25, 2452-2456.

20 Y. Gao, X. Chen, J. Zhang and N. Yan, ChemPlusChem, 2015, 80, 1556-1564.

21 B. Yuan, Z. Chu, G. Li, Z. Jiang, T. Hu, Q. Wang and C. Wang, J. Mater. Chem. C, 2014, 2, 8212-8215.

22 X. Zhang, X. Xie, H. Wang, J. Zhang, B. Pan and Y. Xie, J. Am. Chem. Soc., 2012, 135, 18-21.

23 T. Sano, S. Tsutsui, K. Koike, T. Hirakawa, Y. Teramoto, N. Negishi and K. Takeuchi, J. Mater. Chem. A, 2013, 1, 6489-6496.

24 H. Zhao, H. Yu, X. Quan, S. Chen, Y. Zhang, H. Zhao and H. Wang, Appl. Catal., B, 2014, 152, 46-50.
25 H. Zhao, H. Yu, X. Quan, S. Chen, H. Zhao and H. Wang, RSC $A d v ., 2014,4,624-628$.

26 Y. Li, Z. Wang, T. Xia, H. Ju, K. Zhang, R. Long and J. Jiang, Adv. Mater., 2016, 28, 6959-6965.

27 L. Ge, Mater. Lett., 2011, 65, 2652-2654.

28 X. Bai, L. Wang, R. Zong and Y. Zhu, J. Phys. Chem. C, 2013, 117, 9952-9961.

29 Z. He, D. Wang, J. Tang, S. Song, J. Chen and X. Tao, Environ. Sci. Pollut. Res., 2017, 9, 8219-9229.

30 S. Cao, J. Low, J. Yu and M. Jaroniec, Adv. Mater., 2015, 27, 2150-2176.

31 J. Sehnert, K. Baerwinkel and J. Senker, J. Phys. Chem. B, 2007, 111, 10671-10680.

32 K. Kamiya, R. Kamai, K. Hashimoto and S. Nakanishi, Nat. Commun., 2014, 5, 5040.

33 M. Tahir, C. Cao, F. K. Butt, F. Idrees, N. Mahmood, Z. Ali and T. Mahmood, J. Mater. Chem. A, 2013, 1, 13949-13955.

34 Q. Xiang, J. Yu and M. Jaroniec, J. Phys. Chem. C, 2011, 115, 7355-7363.

35 Y. Li, J. Zhang, Q. Wang, Y. Jin, D. Huang, Q. Cui and G. Zou, J. Phys. Chem. B, 2010, 114, 9429-9434.

36 B. V. Lotsch, M. Döblinger, J. Sehnert, L. Seyfarth, J. Senker, O. Oeckler and W. Schnick, Chem.-Eur. J., 2007, 13, 49694980.

37 V. W. Lau, M. B. Mesch, V. Duppel, V. Blum, J. Senker and B. V. Lotsch, J. Am. Chem. Soc., 2015, 137, 1064-1072.

38 S. M. Lyth, Y. Nabae, S. Moriya, S. Kuroki, M. A. Kakimoto, J. I. Ozaki and S. Miyata, J. Phys. Chem. C, 2009, 113, 20148-20151.

39 B. Jürgens, E. Irran, J. Senker, P. Kroll, H. Müller and W. Schnick, J. Am. Chem. Soc., 2003, 125, 10288-10300.

40 J. R. Holst and E. G. Gillan, J. Am. Chem. Soc., 2008, 130, 7373-7379.

41 S. C. Yan, S. B. Lv, Z. S. Li and Z. G. Zou, Dalton Trans., 2010, 39, 1488-1491. 